\title{
Dermatoglyphic Patterns Among Adolescents of the Ebira Ethnic Group of Kogi State, Nigeria
}

\author{
Abdullateef Onoruoiza Yusuf ${ }^{1}$ (1) Barnabas Danborno ${ }^{1}$ \\ ${ }^{1}$ Department of Human Anatomy, Faculty of Basic Medical Sciences, \\ College of Health Sciences, Ahmadu Bello University, Zaria, Kaduna \\ State, Nigeria \\ 2 Department of Human Anatomy, Faculty of Basic Medical Sciences, \\ College of Health Sciences, Yusuf Maitama Sule University, Kano, \\ Kano State, Nigeria \\ J Morphol Sci 2019;36:261-268.
}

\begin{abstract}
Address for correspondence Abdullateef Onoruoiza Yusuf, BSc, Msc, Department of Human Anatomy, Faculty of Basic Medical Sciences, College of Health Sciences, Ahmadu Bello University, Zaria,

Kaduna State, Nigeria (e-mail: onoruoiza4all@yahoo.com).
\end{abstract}

\begin{abstract}
Dermatoglyphics have been widely studied and have been shown to vary across different ethnic populations. The present study investigates the dermatoglyphic patterns among adolescents of the Ebira ethnic group through selected dialects. A total of 591 subjects, both males and females, participated in the study. Prints were collected by conventional ink and roller method and read using hand magnifying lens. Analyses were performed using descriptive statistics, analysis of variance (ANOVA), $t$-test, and the chi-squared test. P-values $<0.05$ were considered statistically significant. The result of the study showed that the three dialects had similar distribution of fingerprint patterns in the order ulnar loop $>$ whorl $>$ arch $>$ radial loop. The fingerprint pattern showed strong statistical association with gender both within and across the dialects $(p<0.001)$. The palmar crease of the subjects showed the normal palmar crease to be the most prevalent (87\%), followed by the Sidney crease (9\%), and the Suwon crease (4\%) being the least prevalent for both palms across the dialects. There was strong association with palm crease type and gender, with $p<0.001$. The triradii angles of the palms revealed a mean value of acute angles. Females had significantly higher mean atd angles compared with male

Keywords

- dermatoglyphics

- Ebira

- fingerprints

- palmar

- triradii subjects, while males had significant higher mean dat angles compared with females for the three dialects. The adt angle, however, showed no significant mean difference between males and females. In conclusion, the present study evaluated the fingerprint patterns, the palmar creases and the triradii angles conforming anthropological similarities within these three dialects. However, gender differences were observed for the three dialects, with Ebira-Tao and Ebira-Etuno exhibiting shared patterns.
\end{abstract}

\section{Introduction}

Dermatoglyphic traits are widely used markers in analyses of fetal development, developmental disturbances, disease and genetics. ${ }^{1-3}$ The most commonly analyzed dermatoglyphic traits include descriptions of finger patterns and palm patterns; measurements of ridge counts between triradii

received

May 8, 2019

accepted

June 10, 2019
DOI https://doi.org/

10.1055/s-0039-1695755. ISSN 2177-0298. points formed by the convergence of three patterns of ridges; and measurements of the atd angle. ${ }^{4}$

The human body is covered by skin;, however, the skin covering the palmar surface of the hand and the plantar surface of the foot differs both in texture and appearance from that found in other parts of the human body. ${ }^{5}$ The skin on the palmar and plantar surface is continuously wrinkled
Copyright $\odot 2019$ by Thieme Revinter Publicações Ltda, Rio de Janeiro, Brazil
License terms

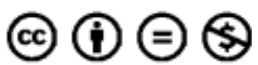


with narrow minute ridges known as friction ridges. ${ }^{5}$ The ridges are the raised portions of skin between furrows on either side. They are also known as papillary or epidermal ridges. The ridges flow in various directions, giving rise to innumerable patterns. ${ }^{6}$

Palmar creases are laid down during the first or second trimester of fetal life ${ }^{7-9}$ and remain unchanged thereafter. ${ }^{10}$ A fetus exposed to trauma during early development could show an increased prevalence of abnormal palmar crease patterns. $^{11}$

Palmar crease variants are classified based on the connection between the three major creases - radial longitudinal, proximal transverse, and distal transverse creases - that slope from the angle near the metacarpophalangeal joint of the index finger. ${ }^{12}$ The studies conducted by Sharma et $\mathrm{al}^{13}$ suggested that the palmar crease is termed as normal when none of the transverse creases traverses entirely from the radial border to the ulnar border of the palm. Infrequently, these creases merge to signify a different thing.

Triradius is the point of confluence from where the ridges usually radiate in three different directions. Schaumann et $\mathrm{al}^{14}$ defined the 'triradius' as the meeting point of 3 ridges that form angles of $\sim 120^{\circ}$ with another. On the palm, there are generally four digital triradii in the distal portion. They are termed as a, b, c, and d, proceeding in the radioulnar direction. The axial triradius ' $t$ ' is found usually near the proximal palmar margin. The triradius close to the palmar axis is termed as axial triradius. It is present normally near the proximal end of the palm and separates the thenar and hypothenar eminences. It is denoted as ' $t$ ' and is usually not $>10 \%$ of the distance between the distal crease of the wrist and the proximal crease of the middle finger. ${ }^{15}$

Dermatoglyphics provide a pertinent area of research to geneticists interested in studying variations within and between populations. ${ }^{16}$ Dermatoglyphics have been used extensively to characterize and differentiate human populations; hence, they are highly suitable for studying population variations. $^{17}$

Ebira, as a name, is used by not less than nine different but historically related groups of people. These are the Ebira Opanda, Ebira Jukun, Ebira Agatu, Ebira Toto, Ebira Abaji, Ebira Koto, Ebira Mozum, Ebira Etuno, and Ebira Tao. The Ebira Koto are found in the riverine area of the Niger-Benue confluence, while the Ebira Etuno inhabit the Igarra area of the Edo State. ${ }^{18}$ The Ebira Tao are found primarily in the Central Senatorial District of the Kogi State, with a sizeable spill over into the Lokoja Local Government Area.

The aim of the present study was to investigate the dermatoglyphic characteristics of the Ebira ethnic group using adolescents from selected secondary schools in the Okene, Igarra, and Koton Karfe local government areas.

\section{Materials and Methods}

The present study was performed in selected secondary schools from the Okene, Igarra, and Koton Karfe local government areas. A total of 591 secondary school subjects participated in the present study, involving males and females from the Ebira-Tao,
Ebira-Etuno, and Ebira-Koto dialects of the Ebira ethnic group of the Kogi state, Nigeria. There was a total of 199 Ebira-Tao participants; 100 males and 99 females; there was a total of 196 Ebira-Etuno participants; 98 males and 98 females; and of 196 Ebira-Koto participants; 97 males and 99 females. The age range of the subjects was between 13 and 17 years old.

The fingerprints were collected using standard ink and roller method according to the modified Cotterman technique. ${ }^{19}$ The fingerprints were taken after washing the hands with soap water and drying them completely. The smeared fingers of both hands were printed on a durable plain paper laid down on a pressure pad that consisted of 10 different blocks for 10 fingers of the right hand and left hand, respectively. The fingerprint pattern of each finger was observed with the help of a hand lens. The fingerprint patterns were classified into loops (ulnar and radial), whorls and arches according to the classification by Penrose et al. ${ }^{20}$

The palm prints were collected using the standard ink and roller method. The right palm was smeared with ink already spread on a glass surface. The inked hand was horizontally pressed against the white plain paper with the fingers and palm thoroughly stretched. Slight pressure on the back of the hand was applied during the printing process. The complete palm print, along with the ridges on the hollow of the palm, as well as the ridges on the metacarpophalangeal areas, were obtained over the plain paper. The same procedure was followed to print the left palm. The palm prints were analyzed with the help of a hand magnifying lens for the type of crease, and for the triradii angles atd, dat, and adt.

Data were presented as frequencies and percentages for each fingerprint and palm crease types. The chi-squared test was also used to test for association between print patterns and gender, as well as print pattern and the different dialects. The chi-squared test was also used to test for the association between palmar crease types and gender. The $t$-test was used to test for mean differences between male and female subjects. Analysis of variance (ANOVA) was used to test for mean differences for the triradii angles between the three dialects.

\section{Results}

The result of the fingerprint patterns for Ebira-Tao subjects, as presented in - Table 1, showed that the ulnar loop pattern has the highest frequency and percentage for all digits, with the radial loop pattern having the lowest frequency and percentages. The whorl pattern is next to the ulnar loop in frequency, followed by the arch. The little finger has the highest occurrence of the ulnar loop ( $n=169$ [84.9\%], and $n=179$ [89.9\%] for the right and left little fingers, respectively [-Table 1]). The radial loop was observed more in the index finger, with frequency and percentage of 12 (6.0\%) and of $21(10.1 \%)$ in the right and left fingers, respectively (-Table 1). The whorl pattern was observed mostly in the thumb, with a frequency of 86 (43.2\%) and of 84 (42.2\%) for the right and left fingers, respectively ( - Table 1 ). The thumb and index fingers had more frequencies of the arch pattern, with similar frequencies (-Table $\mathbf{1}$ ). 
Table 1 Frequency and Percentages of Fingerprint Patterns of Ebira-Tao Subjects

\begin{tabular}{|l|l|l|l|l|l|l|l|l|}
\hline \multirow{2}{*}{ FINGERS } & \multicolumn{4}{|l|}{ Right hand } & \multicolumn{1}{l|}{ Left hand } \\
\cline { 2 - 9 } & $\begin{array}{l}\text { UL } \\
\mathbf{n}(\%)\end{array}$ & $\begin{array}{l}\text { RL } \\
\mathbf{n}(\%)\end{array}$ & $\begin{array}{l}\text { W } \\
\mathbf{n}(\%)\end{array}$ & $\begin{array}{l}\text { A } \\
\mathbf{n}(\%)\end{array}$ & $\begin{array}{l}\text { UL } \\
\mathbf{n}(\%)\end{array}$ & $\begin{array}{l}\text { RL } \\
\mathbf{n}(\%)\end{array}$ & $\begin{array}{l}\text { W } \\
\mathbf{n}(\%)\end{array}$ & $\begin{array}{l}\text { A } \\
\mathbf{n}(\%)\end{array}$ \\
\hline Thumb & $103(51.8)$ & $2(1.0)$ & $86(43.2)$ & $8(4.0)$ & $94(47.2)$ & $1(0.5)$ & $84(42.2)$ & $20(10.1)$ \\
\hline Index & $110(55.3)$ & $12(6.0)$ & $65(32.7)$ & $12(6.0)$ & $108(54.3)$ & $21(10.6)$ & $58(29.1)$ & $12(6.0)$ \\
\hline Middle & $152(76.4)$ & $1(0.5)$ & $41(20.6)$ & $5(2.5)$ & $139(69.8)$ & $5(2.5)$ & $48(24.2)$ & $7(3.5)$ \\
\hline Ring & $119(59.8)$ & $3(1.5)$ & $77(38.7)$ & $0(0.0)$ & $135(67.8)$ & $1(0.5)$ & $62(31.2)$ & $1(0.5)$ \\
\hline Little & $169(84.9)$ & $0(0.0)$ & $29(14.6)$ & $1(0.5)$ & $179(89.9)$ & $1(0.5)$ & $17(8.6)$ & $2(1.0)$ \\
\hline
\end{tabular}

Abbreviations: A, arch; RL, radial loop; UL, ulnar loop; W, whorl.

The result of the fingerprint patterns for Ebira-Etuno subjects, as presented in -Table 2, showed that the ulnar loop pattern had the highest frequency and percentage for all digits, with the radial loop pattern having the lowest frequency and percentages. The whorl pattern was next to the ulnar loop in frequency, followed by the arch. The little finger had the highest occurrence of the ulnar loop $(n=151$ [77.0\%] and $n=166$ [84.7\%] for the right and left little fingers, respectively [-Table 2]). The radial loop was observed more in the index finger, with frequency and percentage of $8(4.1 \%)$ and of 25 $(12.8 \%)$ on the right and left fingers, respectively ( - Table 2 ). The whorl pattern was observed mostly in the thumb, with a frequency of 73 (37.2\%) and of 78 (39.8\%) for the right and left fingers, respectively (- Table 2). However, both the thumb and ring fingers had similar values for the whorl pattern. The thumb and index fingers had higher frequencies of the arch pattern, with similar frequencies (-Table $\mathbf{2}$ ).
The result of the fingerprint patterns for Ebira-Koto subjects, as presented in $\mathbf{- T a b l e ~} \mathbf{3}$, showed that the ulnar loop pattern had the highest frequency and percentage for all digits, with the radial loop pattern having the lowest frequency and percentages. The whorl pattern is next to the ulnar loop in frequency, followed by the arch. The little finger had the highest occurrence of the ulnar loop ( $n=167$ [85.2\%], and $n=177$ [90.3\%] for the right and left little fingers, respectively [ - Table 3$]$ ). The radial loop was observed more in the index finger, with frequency and percentage of $18(9.2 \%)$ and of $16(8.2 \%)$ on the right and left fingers, respectively (-Table 3 ). The whorl pattern was observed mostly in the ring finger, with a frequency of 88 (44.9\%) and of 85 (43.4\%) for the right and left fingers, respectively (-Table 3 ). However, both ring and thumb fingers had similar values for the whorl pattern. The thumb and index fingers had more frequencies of the arch pattern, with similar frequencies (-Table 3 ).

Table 2 Frequency and Percentages of Fingerprint Patterns of Ebira-Etuno Subjects

\begin{tabular}{|c|c|c|c|c|c|c|c|c|}
\hline \multirow[t]{2}{*}{ FINGER } & \multicolumn{3}{|l|}{ Right hand } & \multirow[b]{2}{*}{$\begin{array}{l}\text { A } \\
\text { n (\%) }\end{array}$} & \multicolumn{3}{|l|}{ Left hand } & \multirow[b]{2}{*}{$\begin{array}{l}\text { A } \\
\text { n (\%) }\end{array}$} \\
\hline & $\begin{array}{l}\text { UL } \\
\text { n (\%) }\end{array}$ & $\begin{array}{l}\text { RL } \\
\text { n (\%) }\end{array}$ & $\begin{array}{l}\text { W } \\
\mathrm{n}(\%)\end{array}$ & & $\begin{array}{l}\text { UL } \\
\text { n (\%) }\end{array}$ & $\begin{array}{l}\mathrm{RL} \\
\mathrm{n}(\%)\end{array}$ & $\begin{array}{l}\text { W } \\
\mathrm{n}(\%)\end{array}$ & \\
\hline Thumb & $166(54.1)$ & $0(0)$ & $73(37.2)$ & $17(8.7)$ & $96(49.0)$ & $1(0.5)$ & $78(39.8)$ & $21(10.7)$ \\
\hline Index & $112(57.1)$ & $8(4.1)$ & $60(30.6)$ & $16(8.2)$ & $90(45.9)$ & $25(12.8)$ & $58(29.6)$ & $23(11.7)$ \\
\hline Middle & $150(76.5)$ & $2(1.0)$ & 35 (17.9) & $9(4.6)$ & $133(67.9)$ & $5(2.6)$ & $42(21.4)$ & $16(8.2)$ \\
\hline Ring & $121(61.7)$ & $5(2.6)$ & $66(33.7)$ & $4(2.0)$ & $114(58.2)$ & $4(2.0)$ & $72(36.7)$ & $6(3.1)$ \\
\hline Little & $151(77.0)$ & $0(0)$ & 38 (19.4) & $7(3.6)$ & $166(84.7)$ & $2(1.0)$ & $24(12.2)$ & $4(2.0)$ \\
\hline
\end{tabular}

Abbreviations: A, arch; RL, radial loop; UL, ulnar loop; W, whorl.

Table 3 Frequency and Percentages of Fingerprint Patterns of Ebira-Koto Subjects

\begin{tabular}{|l|l|l|l|l|l|l|l|l|}
\hline \multirow{2}{*}{ FINGER } & \multicolumn{4}{|l|}{ Right hand } & \multicolumn{2}{l|}{ Left hand } \\
\cline { 2 - 9 } & $\begin{array}{l}\text { UL } \\
\mathbf{n}(\%)\end{array}$ & $\begin{array}{l}\text { RL } \\
\mathbf{n}(\%)\end{array}$ & $\begin{array}{l}\text { W } \\
\mathbf{n}(\%)\end{array}$ & $\begin{array}{l}\text { A } \\
\mathbf{n}(\%)\end{array}$ & $\begin{array}{l}\text { UL } \\
\mathbf{n}(\%)\end{array}$ & $\begin{array}{l}\text { RL } \\
\mathbf{n}(\%)\end{array}$ & $\begin{array}{l}\text { W } \\
\mathbf{n}(\%)\end{array}$ & $\begin{array}{l}\text { A } \\
\mathbf{n}(\%)\end{array}$ \\
\hline Thumb & $91(46.4)$ & $1(0.5)$ & $82(41.8)$ & $22(11.2)$ & $8241.8)$ & $2(1.0)$ & $84(42.9)$ & $28(14.3)$ \\
\hline Index & $93(47.4)$ & $18(9.2)$ & $69(35.2)$ & $16(8.2)$ & $78(39.8)$ & $16(8.2)$ & $75(38.3)$ & $27(13.8)$ \\
\hline Middle & $136(69.4)$ & $0(0)$ & $46(23.5)$ & $14(7.1)$ & $126(64.3)$ & $2(1.0)$ & $53(27.0)$ & $15(7.7)$ \\
\hline Ring & $104(53.1)$ & $1(0.5)$ & $88(44.9)$ & $3(1.5)$ & $105(53.6)$ & $2(1.0)$ & $85(43.4)$ & $4(2.0)$ \\
\hline Little & $167(85.2)$ & $0(0)$ & $27(13.8)$ & $2(1.0)$ & $177(90.3)$ & $0(0)$ & $18(9.2)$ & $1(0.5$ \\
\hline
\end{tabular}

Abbreviations: A, arch; RL, radial loop; UL, ulnar loop; W, whorl. 
Table 4 Association Between Fingerprint Patterns and Spoken Dialects within Male Subjects

\begin{tabular}{|c|c|c|c|c|c|c|c|c|c|c|c|c|c|c|c|}
\hline \multirow[t]{2}{*}{ Fingers } & \multirow[b]{2}{*}{ Sides } & \multicolumn{4}{|c|}{$\begin{array}{l}\text { Ebira-Tao } \\
(n=100)\end{array}$} & \multicolumn{4}{|c|}{$\begin{array}{l}\text { Ebira-Etuno } \\
(n=98)\end{array}$} & \multicolumn{4}{|c|}{$\begin{array}{l}\text { Ebira-Koto } \\
(n=97)\end{array}$} & \multirow[b]{2}{*}{$x^{2}$} & \multirow[b]{2}{*}{$p$-value } \\
\hline & & UL & $R L$ & $w$ & $A$ & UL & $R L$ & W & $A$ & UL & $R \mathrm{R}$ & $w$ & A & & \\
\hline \multirow[t]{2}{*}{ Thumb } & $R$ & 50 & 2 & 44 & 4 & 58 & - & 31 & 9 & 45 & 1 & 41 & 10 & 8.707 & 0.191 \\
\hline & $\mathrm{L}$ & 51 & 1 & 36 & 12 & 52 & - & 37 & 9 & 43 & 1 & 40 & 13 & 2.962 & 0.814 \\
\hline \multirow[t]{2}{*}{ Index } & $R$ & 82 & 8 & 1 & 9 & 76 & 6 & 1 & 15 & 43 & 17 & 32 & 5 & 82.089 & $<0.001$ \\
\hline & $\mathrm{L}$ & 75 & 15 & - & 10 & 56 & 19 & 1 & 22 & 39 & 8 & 39 & 11 & 96.680 & $<0.001$ \\
\hline \multirow[t]{2}{*}{ Middle } & $R$ & 94 & 1 & - & 5 & 87 & 2 & - & 9 & 70 & - & 22 & 5 & 51.614 & $<0.001$ \\
\hline & $\mathrm{L}$ & 90 & 4 & - & 6 & 78 & 4 & - & 16 & 67 & 2 & 25 & 3 & 65.658 & $<0.001$ \\
\hline \multirow[t]{2}{*}{ Ring } & $R$ & 97 & 3 & - & - & 88 & 5 & 1 & 4 & 48 & - & 49 & 0 & 125.114 & $<0.001$ \\
\hline & $\mathrm{L}$ & 98 & 1 & - & 1 & 87 & 4 & 1 & 6 & 52 & - & 45 & - & 115.449 & $<0.001$ \\
\hline \multirow[t]{2}{*}{ Little } & $R$ & 99 & - & - & 1 & 91 & - & - & 7 & 86 & - & 11 & - & 33.830 & $<0.001$ \\
\hline & $\mathrm{L}$ & 97 & 1 & - & 2 & 92 & 2 & - & 4 & 90 & - & 7 & - & 20.380 & 0.002 \\
\hline
\end{tabular}

Abbreviations: A, arch; RL, radial loop; UL, ulnar loop; W, whorl; $\mathrm{X}^{2}$, chi-squared. $p<0.05$ is considered statistically significant.

The association between fingerprint patterns and dialects among males of the 3 dialects showed significant association $(p<0.05)$, with exemption of the right and left thumbs (-Table 4). The association between fingerprint patterns and dialects among females of the three dialects showed significant association $(p<0.05)$, with exemption of the right and left thumbs and of the left little fingers ( - Table 5 ).

Both palms of the subjects were studied and were classified into normal, Sidney, and Suwon crease types.

For Ebira-Tao subjects, $85.4 \%$ and $86.4 \%$ of the subjects had the normal crease type for the right and left palms, respectively. A total of $10.6 \%$ and of $11.6 \%$ had the Sidney crease for the right and left palms, while $4.0 \%$ and $2.0 \%$ had the Suwon crease for the right and left palms, respectively ( - Table $\mathbf{6}$ ).

For Ebira-Etuno subjects, $86.7 \%$ and $92.9 \%$ of the subjects had the normal crease type for the right and left palms, respectively. A total of $8.7 \%$ and of $6.1 \%$ had the Sidney crease for the right and left palms, while $4.6 \%$ and $1.0 \%$ had the Suwon crease for the right and left palms, respectively (-Table 6).

For Ebira-Koto subjects, $88.3 \%$ and $89.3 \%$ of the subjects had the normal crease type for the right and left palms, respectively. A total of $10.7 \%$ and $7.7 \%$ had the Sidney crease for the right and left palms, while $1.0 \%$ and $3.0 \%$ had the Suwon crease for the right and left palms, respectively ( - Table 6 ).

For Ebira-Tao subjects, all of the males were observed to have the normal crease for both right and left hands. The females, however, had all the three types of palm creases, with the normal crease being more frequent, and with the Suwon crease being the least frequent for both hands ( - Table 7 ). Statistically significant differences were observed at $p<0.001$ (-Table 7).

Table 5 Association Between Fingerprint Patterns and Spoken Dialects within Female Subjects

\begin{tabular}{|c|c|c|c|c|c|c|c|c|c|c|c|c|c|c|c|}
\hline \multirow[b]{2}{*}{ Fingers } & \multirow[b]{2}{*}{ Sides } & \multicolumn{4}{|c|}{$\begin{array}{l}\text { Ebira-Tao } \\
(n=99)\end{array}$} & \multicolumn{4}{|c|}{$\begin{array}{l}\text { Ebira-Etuno } \\
(n=98)\end{array}$} & \multicolumn{4}{|c|}{$\begin{array}{l}\text { Ebira-Koto } \\
(n=99)\end{array}$} & \multirow[b]{2}{*}{$x^{2}$} & \multirow[b]{2}{*}{ p-value } \\
\hline & & UL & $R L$ & $w$ & $A$ & UL & $\mathrm{RL}$ & $W$ & $A$ & UL & $R L$ & $\mathrm{~W}$ & $A$ & & \\
\hline \multirow[t]{2}{*}{ Thumb } & $\mathrm{R}$ & 53 & - & 42 & 4 & 48 & - & 42 & 8 & 46 & - & 41 & 12 & 4.525 & 0.340 \\
\hline & $\mathrm{L}$ & 43 & - & 48 & 8 & 44 & 1 & 41 & 12 & 39 & 1 & 44 & 15 & 3.989 & 0.678 \\
\hline \multirow[t]{2}{*}{ Index } & $\mathrm{R}$ & 28 & 4 & 64 & 3 & 36 & 2 & 59 & 1 & 50 & 1 & 37 & 11 & 27.405 & $<0.001$ \\
\hline & $\mathrm{L}$ & 33 & 6 & 58 & 2 & 34 & 6 & 57 & 1 & 39 & 8 & 36 & 19 & 29.278 & $<0.001$ \\
\hline \multirow[t]{2}{*}{ Middle } & $R$ & 58 & - & 41 & - & 63 & - & 35 & - & 66 & - & 24 & 9 & 22.931 & $<0.001$ \\
\hline & L & 49 & 1 & 48 & 1 & 55 & 1 & 42 & - & 59 & - & 28 & 12 & 27.697 & $<0.001$ \\
\hline \multirow[t]{2}{*}{ Ring } & $R$ & 22 & - & 77 & - & 33 & - & 65 & - & 56 & 1 & 39 & 3 & 36.670 & $<0.001$ \\
\hline & $\mathrm{L}$ & 37 & - & 62 & - & 27 & - & 71 & - & 53 & 2 & 40 & 4 & 29.624 & $<0.001$ \\
\hline \multirow[t]{2}{*}{ Little } & $R$ & 70 & - & 29 & - & 60 & - & 38 & - & 81 & - & 16 & 2 & 15.982 & 0.003 \\
\hline & $\mathrm{L}$ & 82 & - & 17 & - & 74 & - & 24 & - & 87 & - & 11 & 1 & 7.948 & 0.093 \\
\hline
\end{tabular}

Abbreviations: A, arch; RL, radial loop; UL, ulnar loop; W, whorl; $\mathrm{X}^{2}$, chi-squared.

$p<0.05$ is considered statistically significant. 
Table 6 Frequency and Percentages of Palm Crease Type of the Studied Population

\begin{tabular}{|l|l|l|l|l|l|l|}
\hline & \multicolumn{3}{|l}{ EBIRA-TAO } & \multicolumn{2}{l|}{ EBIRA-ETUNO } & \multicolumn{2}{l|}{ EBIRA-KOTO } \\
\hline PALM CREASE TYPE & $\begin{array}{l}\text { RH } \\
\mathbf{n}(\%)\end{array}$ & $\begin{array}{l}\text { LH } \\
\mathbf{n}(\%)\end{array}$ & $\begin{array}{l}\text { RH } \\
\mathbf{n}(\%)\end{array}$ & $\begin{array}{l}\text { LH } \\
\mathbf{n}(\%)\end{array}$ & $\begin{array}{l}\text { RH } \\
\mathbf{n}(\%)\end{array}$ & $\begin{array}{l}\text { LH } \\
\mathbf{n}(\%)\end{array}$ \\
\hline NORMAL & $170(85.4)$ & $172(86.4)$ & $170(86.7)$ & $182(92.9)$ & $173(88.3)$ & $175(89.3)$ \\
\hline SIDNEY & $21(10.6)$ & $23(11.6)$ & $17(8.7)$ & $12(6.1)$ & $21(10.7)$ & $15(7.7)$ \\
\hline SUWON & $8(4.0)$ & $4(2.0)$ & $9(4.6)$ & $2(1.0)$ & $2(1.0)$ & $6(3.0)$ \\
\hline
\end{tabular}

Abbreviations: $\mathrm{LH}$, left hand; $\mathrm{RH}$, right hand.

Table 7 Association Between Gender and Palm Crease Type in the Studied Population

\begin{tabular}{|c|c|c|c|c|c|c|c|c|c|c|c|c|}
\hline \multirow[b]{2}{*}{$\begin{array}{l}\text { Palm } \\
\text { crease }\end{array}$} & \multicolumn{4}{|l|}{ Ebira-Tao } & \multicolumn{4}{|c|}{ Ebira-Etuno } & \multicolumn{4}{|c|}{ Ebira-Koto } \\
\hline & $\begin{array}{l}\text { Males } \\
(n=100)\end{array}$ & $\begin{array}{l}\text { Females } \\
(n=99)\end{array}$ & $x^{2}$ & p-value & $\begin{array}{l}\text { Males } \\
(n=98)\end{array}$ & $\begin{array}{l}\text { Females } \\
(n=98)\end{array}$ & $x^{2}$ & p-value & $\begin{array}{l}\text { Males } \\
(n=97)\end{array}$ & $\begin{array}{l}\text { Females } \\
(n=99)\end{array}$ & $x^{2}$ & $p$-value \\
\hline \multicolumn{13}{|l|}{$\begin{array}{l}\text { Right } \\
\text { palm }\end{array}$} \\
\hline Normal & 100 & 70 & \multirow[t]{3}{*}{34.290} & \multirow[t]{3}{*}{$<0.001$} & 98 & 72 & \multirow[t]{3}{*}{29.976} & \multirow[t]{3}{*}{$<0.001$} & 86 & 87 & \multirow[t]{3}{*}{0.033} & \multirow[t]{3}{*}{0.984} \\
\hline Sidney & 0 & 21 & & & 0 & 17 & & & 10 & 11 & & \\
\hline Suwon & 0 & 8 & & & 0 & 9 & & & 1 & 1 & & \\
\hline \multicolumn{13}{|l|}{$\begin{array}{l}\text { Left } \\
\text { palm }\end{array}$} \\
\hline Normal & 100 & 72 & \multirow[t]{3}{*}{31.554} & \multirow[t]{3}{*}{$<0.001$} & 98 & 84 & \multirow[t]{3}{*}{15.077} & \multirow[t]{3}{*}{0.001} & 85 & 90 & \multirow[t]{3}{*}{0.856} & \multirow[t]{3}{*}{0.652} \\
\hline Sidney & 0 & 23 & & & 0 & 12 & & & 8 & 7 & & \\
\hline Suwon & 0 & 4 & & & 0 & 2 & & & 4 & 2 & & \\
\hline
\end{tabular}

For Ebira-Etuno subjects, all the males were observed to have the normal crease for both right and left hands. The females, however, had all the three types of palm crease, with the normal being more frequent, and the Suwon crease being the least frequent for both hands, just as seen in the Ebirakoto subjects ( - Table 7 ). Statistical significant differences were observed at $p<0.001$ ( - Table 7 ).

For Ebira-Koto subjects, both males and females were observed to have all the three palm crease types. However, the normal crease was more frequent, followed by the Sidney crease, with the Suwon crease being the least frequent for both hands in male and female subjects ( - Table 7). However, there was no significant association ( - Table 7 ).

The right and left tri radii atd and dat angles showed statistically significant differences in mean values between males and females in the Ebira-Tao and Ebira-Etuno dialects; with the females having higher mean atd angles for both hands, and males having higher mean dat angles ( - Table 8 ). The Ebira-Koto dialect, however had similar results as the Ebira-Tao and Ebira-Etuno dialects (females having higher mean atd angles for both hands and males having higher mean dat angles), but showed no statistically significant difference ( - Table 8).

The males of the three studied dialects showed no statistically mean differences in their right and left tri radii angles (-Table 9). The females of the three dialects showed no statistically mean differences in their tri radii angles for both hands (-Table 10).

\section{Discussion}

The frequency of the digital print patterns of all the studied subjects of the Ebira ethnic group in the Kogi state, Nigeria, was inconsistent with the findings of previous researchers in Nigeria and in other parts of the world. ${ }^{21-25}$ The percentage frequency for both hands showed that the ulnar loop pattern had the highest frequency in both genres, followed by the whorl pattern; the arch was next, and the radial loop pattern was least prevalent. These findings were similar for the Ebira-Tao, EbiraEtuno, and Ebira-Koto dialects, as shown in - Tables 1,2,3.

The total percentages of fingerprints patterns for all 10 fingers in Ebira-Tao subjects were found to be: ulnar loop, 65.7\%; radial loop, $2.4 \%$; whorl, $28.5 \%$; and arch, 3.4\%. For EbiraEtuno subjects, the total percentages of patterns for all 10 fingerprints were: ulnar loop, 63.2\%; radial loop, 2.7\%; whorl, 27.8\%; and arch, 6.3\%. For Ebira-Etuno subjects, the total percentages of patterns for all 10 fingerprints were: ulnar loop, 59.1\%; radial loop, 2.1\%; whorl, 32.0\%; and arch, $6.8 \%$. These findings revealed that the three studied dialects (EbiraTao, Ebira-Etuno and Ebira-Koto) had similar characteristics in fingerprints patterns in the form of ulnar loop $>$ whorl $>$ arch $>$ radial loop; although the values for each dialect differs. These similarities in the findings of these three dialects are possibly an indication of their common ancestry. These percentages for the fingerprint patterns were inconsistent with reports by Odokuma et $\mathrm{al}^{22}$ among students in Delta, by Osunwoke et $\mathrm{al}^{23}$ among the Okrika and Ikwere ethnic groups, by Umana et $\mathrm{al}^{25}$ 


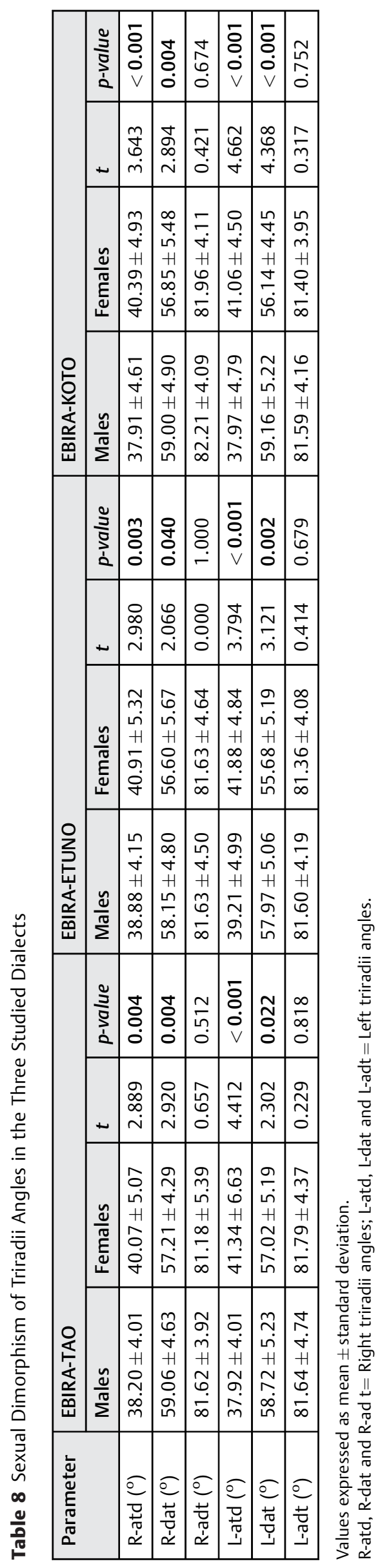

in Abuth Zaria, by Danborno et $\mathrm{al}^{26}$ among the Hausa ethnic group of Nigeria, who all reported a higher percentage of the loop pattern. The work of Biswas ${ }^{17}$ among the Indian population, and of Etta et $\mathrm{al}^{27}$ among the Cross river people, however, reported the highest frequency of the whorl pattern, followed by the loop pattern.

It was observed that males had a higher percentage of the ulnar, arch and radial loop patterns, while the females had a higher percentage of the whorl pattern. These gender differences were statistically significant $(p<0.05)$ in almost all of the fingers, with the Ebira-Koto dialect having the least statistically significant difference. The observed gender differences in fingerprint patterns could be due to gender differences in trait heritability from the parents and to developmental variation between genres. ${ }^{28,29}$ The analysis of the data showed that the Ebira-Tao and Ebira-Etuno dialects had similar fingerprint patterns, with a slight difference from the Ebira-Koto dialect.

The males of three studied dialects showed a strong association $(p<0.001)$ between fingerprint patterns and dialects. However, the right thumb and left thumb showed no significant association. Male subjects of Ebira-Tao and Ebira-Etuno had the lowest occurrence of the whorl pattern, with the pattern seen mainly in the thumb and index fingers, as opposed to males of the Ebira-Koto dialect, who had occurrence of the whorl pattern in all of the fingers (-Table 4). These findings showed that the males of the Ebira-Tao and Ebira-Etuno dialects have more similarities in their fingerprint patterns compared with Ebira-Koto males.

The females of three studied dialects showed a strong association $(p<0.001)$ between fingerprint patterns and dialects. However, the right thumb, the left thumb, and the left little finger showed no significant association. Female subjects of Ebira-Tao and Ebira-Etuno had the lowest occurrence of the arch pattern, with this pattern not observed in the right and left ring and little fingers. This was opposed to the findings in females of the Ebira-Koto dialect, who had occurrence of the arch pattern in all of the fingers ( - Table 5 ). These findings showed that the females of Ebira-Tao and Ebira-Etuno subjects have more similarities in their fingerprint patterns when compared with Ebira-Koto females.

Palm crease types have been investigated by many researchers, and in some cases investigations were done to observe their possible relation with numerical chromosomal aberrations. In the present study, the palm creases of seemingly healthy subjects were observed for their distribution in the population. The study revealed $>85 \%$ to be normal for the three dialects, followed by the Sidney crease, with the Suwon crease being the least common. Earlier researchers have reported similar findings, although in different population; Alhaji et $\mathrm{al}^{30}$ among the Hausa; Taura et $\mathrm{al}^{31}$ still among Hausas; but a comparative study (between normal and epileptic persons); Oyinbo et al $^{32}$ among the Ijaw ethnic group of Nigeria, all of which reported the highest frequency of the normal crease. Our findings, however, had no occurrence of the Simian crease. The work of Alhaji et al, ${ }^{30}$ however, reported that $\sim 8 \%$ among the Hausa had the Simian crease, and Oyinbo et $\mathrm{al}^{32}$ also reported $4.1 \%$ of the Simian crease among the Ijaw ethnic group. This inter-ethnic 
Table 9 Comparison of the Triradii Angle Among Males of the Three Studied Dialects

\begin{tabular}{|c|c|c|c|c|c|}
\hline \multirow[t]{2}{*}{ Parameters } & $\begin{array}{l}\text { EBIRA-TAO } \\
(n=100)\end{array}$ & $\begin{array}{l}\text { EBITA-ETUNO } \\
(n=98)\end{array}$ & $\begin{array}{l}\text { EBIRA-KOTO } \\
(n=97)\end{array}$ & & \\
\hline & Mean \pm SD & Mean \pm SD & Mean \pm SD & $f$ & p-value \\
\hline R-atd $\left({ }^{\circ}\right)$ & $38.20 \pm 4.01$ & $38.88 \pm 4.15$ & $37.91 \pm 4.61$ & 1.331 & 0.266 \\
\hline R-dat $\left({ }^{\circ}\right)$ & $59.06 \pm 4.63$ & $58.15 \pm 4.80$ & $59.00 \pm 4.90$ & 1.108 & 0.332 \\
\hline R-adt $\left({ }^{\circ}\right)$ & $81.62 \pm 3.92$ & $81.63 \pm 4.50$ & $82.21 \pm 4.09$ & 0.628 & 0.534 \\
\hline L-atd $\left({ }^{\circ}\right)$ & $37.92 \pm 4.01$ & $39.21 \pm 4.99$ & $37.97 \pm 4.79$ & 2.489 & 0.085 \\
\hline L-dat $\left({ }^{\circ}\right)$ & $58.72 \pm 5.23$ & $57.97 \pm 5.06$ & $59.16 \pm 5.22$ & 1.334 & 0.265 \\
\hline L-adt $\left({ }^{\circ}\right)$ & $81.64 \pm 4.74$ & $81.60 \pm 4.19$ & $81.59 \pm 4.16$ & 0.004 & 0.996 \\
\hline
\end{tabular}

Abbreviation: SD, standard deviation.

R-atd, R-dat and R-adt $=$ Right triradii angles; L-atd, L-dat and L-adt $=$ Left triradii angles.

Table 10 Comparison of the Triradii Angle Among Females of the Three Studied Dialects

\begin{tabular}{|c|c|c|c|c|c|}
\hline \multirow[t]{2}{*}{ Parameters } & $\begin{array}{l}\text { EBIRA-TAO } \\
(n=99)\end{array}$ & $\begin{array}{l}\text { EBIRA-ETUNO } \\
(n=98)\end{array}$ & $\begin{array}{l}\text { EBIRA-KOTO } \\
(n=99)\end{array}$ & & \\
\hline & Mean \pm SD & Mean \pm SD & Mean \pm SD & $f$ & $p$-value \\
\hline R-atd $\left({ }^{\circ}\right)$ & $40.07 \pm 5.07$ & $40.91 \pm 5.32$ & $40.39 \pm 4.93$ & 0.673 & 0.511 \\
\hline R-dat $\left({ }^{\circ}\right)$ & $57.21 \pm 4.29$ & $56.60 \pm 5.67$ & $56.85 \pm 5.48$ & 0.346 & 0.708 \\
\hline R-adt $\left({ }^{\circ}\right)$ & $81.18 \pm 5.39$ & $81.63 \pm 4.64$ & $81.96 \pm 4.11$ & 0.672 & 0.512 \\
\hline L-atd $\left({ }^{\circ}\right)$ & $41.34 \pm 6.63$ & $41.88 \pm 4.84$ & $41.06 \pm 4.50$ & 0.579 & 0.561 \\
\hline L-dat $\left({ }^{\circ}\right)$ & $57.02 \pm 5.19$ & $55.68 \pm 5.19$ & $56.14 \pm 4.45$ & 1.853 & 0.159 \\
\hline L-adt $\left({ }^{\circ}\right)$ & $81.79 \pm 4.37$ & $81.36 \pm 4.08$ & $81.40 \pm 3.95$ & 0.332 & 0.725 \\
\hline
\end{tabular}

Abbreviation: SD, standard deviation.

R-atd, R-dat and R-adt $=$ Right triradii angles; L-atd, L-dat and L-adt $=$ Left triradii angles.

variation could be due to difference means of classifying the crease or, possibly, to inter-ethnic differences themselves.

The sexual dimorphism study showed that both the Sidney and Suwon crease types did not feature among the males of Ebira-Tao and Ebira-Etuno subjects. Sharma et al ${ }^{13}$ had reported the Sydney crease to be more common among the females than among the males, but the work of Alhaji et $\mathrm{al}^{30}$ however, reported no Sidney crease among the palms of female subjects. For the Ebira-Koto, both males and females presented with Sidney and Suwon crease types in almost similar percentages. Therefore, this finding showed that Ebira-Tao and Ebira-Etuno subjects had more related palm crease types when compared with Ebira-Koto.

The tri-radii angles of both hands were investigated in the studied subjects. The tri-radii angles investigated were tri-radii atd, dat and adt angles. The findings from the study showed that tri-radii atd, dat and adt angles had similar mean values of for the right and left hands. The mean values for the three tri-radii angles were all $<90^{\circ}$ (acute angles). The works of Khairnar et $\mathrm{al}^{33}$ of Navgire et $\mathrm{al}^{34}$ and of Chaudhari et $\mathrm{al}^{35}$ have all reported mean tri-radii angles values of similar range. There were significant $(p<0.05)$ higher tri-radii atd angles observed in the female subjects compared with the males for the three studied dialects. Pakhale et $\mathrm{al}^{36}$ performed a similar study among Indians and reported higher tri-radii atd angles in female subjects of both healthy and bronchial asthmatic patients compared with males. The observed statistical mean difference between male and female subjects of Ebira-Tao and Ebira-Etuno could be a result of gender differences in the heritability of traits.

Tri-radii dat angle results showed significant $(p<0.05)$ higher mean values in males compared with female subjects for Ebira-Tao and Ebira-Etuno dialects. Although Ebira-Koto subjects showed no statistically significant mean difference between male and female subjects, the mean tri radii dat was also higher in the male subjects. The tri-radii adt angle, however, showed no statistical significant difference for the three dialects studied. These findings showed that the three dialects have similar tri-radii characteristics, suggesting a possible common ancestry.

\section{Conclusions}

From the present study, the fingerprint patterns of adolescents of the Ebira ethnic group followed a particular pattern of percentage frequency, which is ulnar loop $>$ whorl $>$ arch $>$ radial loop, which implies similarities in the Ebira-Tao, Ebira-Etuno and Ebira-Koto dialects. Gender differences were observed between males of each dialect. Males of Ebira-Tao and Ebira-Etuno dialects have more similar patterns and distribution of fingerprint, like their females, indicating more similarities in the Ebira-Tao and Ebira-Etuno dialects, compared with the Ebira-Koto dialect. 
The three dialects have a similar palmar crease distribution. The normal palmar crease was the most prevalent among the seemingly normal population of the Ebira ethnic group, followed by the Sidney palm crease, with the Suwon palm crease being the least prevalent. Only the females of Ebira-Tao and Ebira-Etuno subjects had the Sidney and Suwon palm creases, while both males and females of Ebira-Koto subjects had all the three palm crease types. Association between gender and palm creases was observed for Ebira-Tao and Ebira-Etuno subjects. This finding also showed more closeness of Ebira-Tao and Ebira-Etuno dialects.

The tri-radii atd, dat and adt angles of the subjects revealed mean acute angles for all the three studied dialects in the order atd $<$ dat $<$ adt angle.

Conflicts of Interests

The authors have no conflicts of interests to declare.

\section{Acknowledgments}

We wish to acknowledge the research assistance for their tireless effort during the study. We would also like to acknowledge the authorities of the schools where the study was performed.

\section{References}

1 Devcić S, Mihanović M, Milicić J, Glamuzina L, Silić A. Comparative study on dermatoglyphics in alcoholic patients. Coll Antropol 2009;33(04):1311-1318

2 Temaj G, Milicić J, Skarić Jurić T, et al. Comparative analysis of dermatoglyphic traits in Albanian and Turkish population living in Kosovo. Coll Antropol 2009;33(04):1001-1005

3 Namouchi I. Anthropological significance of dermatoglyphic trait variation: an intra-Tunisian population analysis. Int. J. Mod. Anthropol. 2011;4:12-27

4 Brunson EK, Hohnan DJ, Giovas CM. Reliability of the atd angle in dermatoglyphic analysis. Coll Antropol 2015;39(03):797-800

5 Desai B, Jaiswal R, Tiwan P, Kalyan JL. Study of finger print patterns in relationship with blood group and gender- a statistical review. Res. J. Foren. Sci. 2013;1:15-17

6 Ganapati MT. Identification of an individual through fingerprints. J. Biol. Innov. 2013;2(02):59-72

7 Johnson CF, Opitz E. The single palmar crease and its clinical significance in a child development clinic. Clin Pediatr (Phila) 1971;10(07):392-403

8 Dar H, Schmidt R, Nitowsky HM. Palmar crease variants and their clinical significance: a study of newborns at risk. Pediatr Res 1977;11(02):103-108

9 Cannon M, Byrne M, Cotter D, Sham P, Larkin C, O'Callaghan E. Further evidence for anomalies in the hand-prints of patients with schizophrenia: a study of secondary creases. Schizophr Res 1994;13(02):179-184

10 Tay JS. The genetics of palmar creases. A study in the inheritance of liability estimated from the incidence among relatives. Ann Hum Genet 1979;42(03):327-332

11 Purvis-Smith SG, Hayes K, Menser MA. Dermatoglyphics in children with prenatal cytomegalovirus infection. Lancet 1972;2 (7784):976-977

12 Park JS, Shin DS, Jung W, Chung MS. Improved analysis of palm creases. Anat Cell Biol 2010;43(02):169-177
13 Sharma DK, Sharma V. Prevalence of Simian, Sydney and Suwon creases and their association with each other, body sides, handedness, gender and anomalies/ diseases/syndromes in a population of Central India. Int J Morphol 2010;29(03):1069-1075

14 Schaumann B, Alter M. Dermatoglyphics in medical disorders. Springer-VerlagNew York258

15 Neiswanger K, Cooper ME, Weinberg SM, et al. Cleft lip with or without cleft palate and dermatoglyphic asymmetry: evaluation of a Chinese population. Orthod Craniofac Res 2002;5(03):140-146

16 Reddy BKC, Reddy KSN. A study of palmar dermatoglyphics among Sugalis, a tribal population of Andhra Pradesh. Anthropol. 2006;8(01):21-24

17 Biswas S. Finger and palmar dermatoglyphic study among the Dhimals of North Bergal, India. Anthropol. 2011;13(03): 235-238

18 Salami SS. In: The heritage of Ebira Tao. Vol 1. Dima Printers; 2011

19 Cotterman CW. A Scotch-tape India-ink method for recording dermatoglyphs. Am J Hum Genet 1951;3(04):376-379

20 Penrose LS, Loesch D. The effect of sex chromosomes characteristics of dermal ridges on palms and fingerprints. Genet Pol. 1970; 10:328-332

21 Cummins H. Epidermal-ridge configurations in developmental defects, with particular reference to the ontogenetic factors which condition ridge direction. Am J Anat 1926;38:89-151

22 Odokuma EI, Igbigbi PS. Digital dermatoglyphics in students of Delta State University, Nigeria. J. Exp. Clin. Anat. 2005;4(01):30-32

23 Osunwoke EA, Ordu KS. Hart J, Esomunu C and Tamunokuro FB. A study on the dermatoglyphic patterns of Okrika and Ikwerre ethnic groups of Nigeria. Sci. Afr. 2008;7(02):143-147

24 Udoaka AI, Udoaka EG. Digital dermatoglyphics in Ijaw students of university of Port Harcourt, Nigeria. Cont.J. Biomed. Sci. 2009;3:1-5

25 Umana UE, Bello R, Timbuak JA, et al. Dermatoglyphic and cheiloscopic patterns among diabetic patients: a study in Ahmadu Bello University Teaching Hospital Zaria, Nigeria. J Biol Life Sci 2013;4(02):206-214

26 Danborno B, Idris G. Digital dermatoglyphics of Hausa ethnic group of Nigeria. J. Exp. Clin. Anat 2007;6(1\&2):36-40

27 Etta H, Petu I, Etukudoh I, Uyannah D. Dermatoglyphic variation in Nigerian population. J Sci Eng Technol 2014;3(02):25-28

28 Meier R. Anthropological dermatoglyphics: a review. Yearb Phys Anthropol 1980;23:147-178

29 Imene N. Dermatoglyphic trait variation: an intra- Tunisian population analysis. Int. J. Mod. Anthropol. 2011;4:12-27

30 Alhaji MM, Timbuak JA, Umana UE, Tanko M. Palmar creases and handedness in Hausas of northern Nigeria: a cross-sectional study. Asian J. Biol. Med. Sci. 2015;1(02):6-13

31 Taura AA, Taura MG, Adamu LH. Palmar creases; A comparative study between epilepsy patients and healthy subjects among Hausas of Northern Nigeria. Am J Med Sci 2014;4(05): $175-179$

32 Oyinbo CA, Fawehinmi HB. Prevalence of Simian and Sydney creases in the Ijaws of South- South Nigeria. Int. J. Biol. Anthropol. 2009;3(02):59-65

33 Khairnar KB, Kate DP, Bhusari PA, Shukla K. Palmar dermatoglyphics and pulmonary tuberculosis. Int J Health Sci Res 2012;2 (02):54-63

34 Navgire VR, Meshram MM. Study of palmar dermatoglyphics in pulmonary tuberculosis.. Int. J. Res. Rev. 2013;5(14):111-114

35 Chaudhari JS, Sarvaiya BJ, Patel SM, Patel SV. Study of atd angle, finger ridge count in pulmonary tuberculosis patients. Int. J. Anat. Res. 2015;3(04):1520-1525

36 Pakhale SV, Mahajan AA, Doshi MA. Study of 'atd' angle as dermatoglyphic feature in bronchial asthma. Int J Health Sci Res 2012;2(04):13-16 